\title{
Ocular inflammatory events following COVID-19 vaccination: a multinational case series
}

\author{
Ilaria Testi ${ }^{1} \mathbb{D}$, Camilo Brandão-de-Resende ${ }^{2}$, Rupesh Agrawal1 ${ }^{1,3,4,5,6}$, Carlos Pavesio ${ }^{1 *}$ and for the COVID-19 \\ Vaccination Ocular Inflammatory Events Study Group
}

\begin{abstract}
Background: Inflammatory adverse events following COVID-19 vaccination are being reported amidst the growing concerns regarding vaccine's immunogenicity and safety, especially in patients with pre-existing inflammatory conditions.

Methods: Multinational case series of patients diagnosed with an ocular inflammatory event within 14 days following COVID-19 vaccination collected from 40 centres over a 3 month period in 2021.

Results: Seventy patients presented with ocular inflammatory events within 14 days following COVID-19 vaccination. The mean age was 51 years (range, 19-84 years). The most common events were anterior uveitis $(n=$ $41,58.6 \%)$, followed by posterior uveitis $(n=9,12.9 \%)$ and scleritis $(n=7,10.0 \%)$. The mean time to event was 5 days and 6 days (range, 1-14 days) after the first and second dose of vaccine, respectively. Among all patients, 36 (54.1\%) had a previous history of ocular inflammatory event. Most patients $(n=48,68.6 \%)$ were managed with topical corticosteroids. Final vision was not affected in 65 (92.9\%), whereas 2 (2.9\%) and 3 (4.3\%) had reduction in visual acuity reduced by $\leq 3$ lines and $>3$ lines, respectively. Reported complications included nummular corneal lesions $(n=1,1.4 \%)$, cystoid macular oedema $(n=2,2.9 \%)$ and macular scarring $(n=2,2.9 \%)$.

Conclusion: Ocular inflammatory events may occur after COVID-19 vaccination. The findings are based on a temporal association that does not prove causality. Even in the possibility of a causal association, most of the events were mild and had a good visual outcome.
\end{abstract}

Keywords: Uveitis, Ocular inflammation, Immunomodulatory, Coronavirus disease, COVID-19, SARS-CoV-2, Vaccination

The most common ocular manifestation of COVID-19, the disease cause by SARS-CoV-2, includes conjunctivitis, with reported cases of keratitis, keratoconjunctivitis, episcleritis, uveitis, posterior ischemic optic neuropathy and retinal vascular involvement [1-4]. In December 2020, the Food and Drug Administration (FDA) released the emergency use authorisation for the PfizerBioNTech and Moderna COVID-19 vaccine for the

\footnotetext{
* Correspondence: c.pavesio@nhs.net

'Department of Uveitis, Moorfields Eye Hospital, NHS Foundation Trust, London, UK

Full list of author information is available at the end of the article
}

prevention of 2019 coronavirus disease, whereas the Oxford-AstraZeneca COVID-19 vaccine was authorised by the European Medicines Agency (EMA) soon after in January 2021. Currently, there are four types of COVID19 vaccines available, including the messenger RNA (mRNA) vaccines (Pfizer-BioNTech and Moderna); the protein subunit vaccines (Novavax); the vector vaccines (Janssen Johnson \& Johnson and Oxford-AstraZeneca), and the whole virus vaccines (Sinovac13, Sinopharm14 and Covaxin). Inflammatory adverse events, including myocarditis and pericarditis, have been reported to occur following COVID-19 vaccination $[5,6]$. The 
objective of this study is to describe the spectrum and outcome of ocular inflammatory events associated with the administration of COVID-19 vaccination.

\section{Methods}

Case series of patients diagnosed with an ocular inflammatory event after receiving COVID-19 vaccination collected from 40 international centres over a 3 month period in 2021 (see group information). The study was conducted with ethical approval obtained by the leading centre from its local institutional ethics committee (ethics approval: 2021/00438). The diagnosis of COVID-19 vaccination related-ocular inflammation was established based on the onset of the event within 14 days following COVID-19 vaccination and the patients who satisfied this specific criteria were only recruited for this report. A form for data collection was sent to all International Ocular Inflammation Society (IOIS) and International Uveitis Study Group (IUSG) members. Clinicians who observed an ocular inflammatory event within 14 days following COVID19 vaccination filled out the form. The following information were retrieved from patients' medical records: type of COVID-19 vaccination, timing of the events, including date of vaccination and date of onset of uveitis, past ocular history, type of ocular inflammatory event, including scleritis, episcleritis, anterior uveitis, posterior uveitis, intermediate uveitis, panuveitis, and optic neuritis, local and systemic treatment history, therapeutic management and outcome.

\section{Data collection}

A purpose built data entry platform was created to collect the ocular inflammatory adverse reactions to COVID-19 vaccination. The secure encrypted web-based platform was programmed by CP, RA and IT. Given the observational and retrospective nature of the data, multiple imputations were not allowed. Ninety-four cases were collected, however, 24 had the event, 2 weeks after the vaccination and were excluded from the analysis, resulting in 70 cases. Statistical analysis was done using the software R v 4.1.1 [R Core Team (2021). R: A language and environment for statistical computing. $\mathrm{R}$ Foundation for Statistical Computing, Vienna, Austria]. Continuous variables were described as median [range] while binary variables were described as number (\%).

\section{Results}

Seventy patients presented with ocular inflammatory events within 14 days following COVID-19 vaccination, and the most common were anterior uveitis $(n=41$, $58.6 \%)$, posterior uveitis $(n=9,12.9 \%)$, and anterior scleritis $(n=7,10.0 \%)$. The study population and the corresponding phenotypes is described in Table 1 with the details of ocular inflammatory events in Table 2.

Forty-one patients had anterior uveitis after vaccination, of which nine (22.0\%) had history of HLA-B27 associated uveitis (one was on secukinumab and one on infliximab plus methotrexate), six (14.6\%) had idiopathic anterior uveitis, three $(7.3 \%)$ had glaucomatocyclitic crisis (one on topical corticosteroids), two (4.9\%) with herpetic anterior uveitis, one (2.4\%) of juvenile idiopathic arthritis associated uveitis (on adalimumab), one (2.4\%) of Cytomegalovirus (CMV) uveitis and one (2.4\%) of systemic lupus erythematosus uveitis (on hydroxychloroquine). All the events after vaccination in these patients were similar to their previous ones. Two patients (4.9\%) presented with herpetic anterior uveitis for the first time and no other new diagnosis was made for any other patient. Two patients $(4.9 \%)$ had persistent visual loss on the last follow-up, one (2.4\%) due to cystoid macular oedema (visual acuity (VA) reduced $\leq 3$ lines) and one (2.4\%) due to nummular corneal lesions (VA reduced > 3 lines).

Nine patients had posterior uveitis after vaccination, of which $2(22.2 \%)$ had history of ocular toxoplasmosis, and one $(11.1 \%)$ of acute zonal occult outer retinopathy (AZOOR). The patients with history of ocular toxoplasmosis presented with recurrence of lesions and the patient with AZOOR had a different presentation from previous events, with multifocal choroiditis. Three patients $(33.3 \%)$ presented with ocular toxoplasmosis, two (22.2\%) presented with retinal vasculitis, and one (11.1\%) presented with choroiditis for the first time. One patient (11.1\%) with ocular toxoplasmosis, and one (11.1\%) with occlusive retinal vasculitis had persistent visual loss on the last follow-up due to macular scarring.

Seven patients had anterior scleritis after vaccination, of which four (57.1\%) had history of idiopathic anterior scleritis, and one (14.3\%) of idiopathic posterior scleritis (on methotrexate and prednisolone). All the events after vaccination in these patients were similar to their previous ones. Two patients (28.6\%) presented anterior scleritis for the first time. All patients had unaffected visual acuity after the event.

Other events $(N=13,18.6 \%)$ included panuveitis $(N=$ $3,4.3 \%)$, optic neuritis $(N=2,2.9 \%)$, episcleritis $(\mathrm{N}=2$, $2.9 \%)$, intermediate uveitis $(\mathrm{N}=2,2.9 \%)$, paracentral acute middle maculopathy $(\mathrm{N}=1,1.4 \%)$, giant cell arteritis $(\mathrm{N}=1,1.4 \%)$, periocular skin herpes zoster $(\mathrm{N}=1$, $1.4 \%)$, and unspecific blurriness of vision $(\mathrm{N}=1,1.4 \%)$. Among these patients, one (7.7\%) had history of intermediate uveitis (was on mycophenolic acid), one (7.7\%) of idiopathic panuveitis (was on azathioprine), one (7.7\%) of optic neuritis, one (7.7\%) of CMV anterior uveitis, and one $(7.7 \%)$ of episcleritis. The events after vaccination in these patients were similar to their previous 
Table 1 Description of the study population by the type of event $(n=70)$

\begin{tabular}{|c|c|c|c|c|c|c|}
\hline & Variable & Total (\%) & $\begin{array}{l}\text { Anterior Uveitis } \\
\text { (\%) }\end{array}$ & $\begin{array}{l}\text { Posterior Uveitis } \\
\text { (\%) }\end{array}$ & $\begin{array}{l}\text { Scleritis } \\
(\%)\end{array}$ & $\begin{array}{l}\text { Others } \\
\text { (\%) }\end{array}$ \\
\hline \multirow[t]{5}{*}{ Demographics } & Number of Patients & $70(100.0)$ & $41(58.6)$ & $9(12.9)$ & $7(10.0)$ & $13(18.6)$ \\
\hline & ${ }^{*}$ Age (years) & 51 [19-84] & 55 [19-84] & $40[28-61]$ & $48[40-52]$ & $54[25-79]$ \\
\hline & ${ }^{*}$ Gender $=$ Female & $35(56.5)$ & $19(52.8)$ & $4(44.4)$ & $6(85.7)$ & $6(60)$ \\
\hline & ${ }^{*}$ Gender $=$ Male & $27(43.5)$ & $17(47.2)$ & $5(55.6)$ & $1(14.3)$ & $4(40)$ \\
\hline & History of Previous COVID-19 & $1(1.4)$ & $1(2.4)$ & $0(0.0)$ & $0(0.0)$ & $0(0.0)$ \\
\hline \multirow[t]{5}{*}{ Vaccine } & Pfizer & $40(57.1)$ & $20(48.8)$ & $4(44.4)$ & $5(71.4)$ & $11(84.6)$ \\
\hline & Astra-Zeneca & $17(24.3)$ & $12(29.3)$ & $4(44.4)$ & $1(14.3)$ & $0(0)$ \\
\hline & Moderna & $10(14.3)$ & $7(17.1)$ & $1(11.1)$ & $1(14.3)$ & $1(7.7)$ \\
\hline & Sinopharm & $2(2.9)$ & $1(2.4)$ & $0(0)$ & $0(0.0)$ & $1(7.7)$ \\
\hline & Covaxin & $1(1.4)$ & $1(2.4)$ & $0(0)$ & $0(0.0)$ & $0(0)$ \\
\hline \multirow[t]{4}{*}{ Event After First Dose } & Number of Patients & $43(61.4)$ & $22(53.7)$ & $6(66.7)$ & $4(57.1)$ & $11(84.6)$ \\
\hline & Time After First Dose [days] & $6[1-14]$ & $5.5[1-14]$ & $6.5[1-14]$ & $4.5[1-9]$ & $8[1-14]$ \\
\hline & Received Another Dose & $18(41.9)$ & $11(50)$ & $3(50)$ & $1(25)$ & $3(27.3)$ \\
\hline & Recurrence After Second Dose & $\begin{array}{l}6 / 18 \\
(33.3)\end{array}$ & $5 / 11(45.5)$ & $0(0.0)$ & $1 / 4(25.0)$ & $0(0.0)$ \\
\hline \multirow{2}{*}{$\begin{array}{l}\text { Event After Second } \\
\text { Dose }\end{array}$} & Number & 27 (39.6) & $19(46.3)$ & $3(33.3)$ & $3(42.9)$ & $2(15.4)$ \\
\hline & $\begin{array}{l}\text { Time After Second Dose } \\
\text { [days] }\end{array}$ & $5[1-14]$ & $5[1-14]$ & 8 [2-9] & $4[2-14]$ & $7[2-12]$ \\
\hline
\end{tabular}

${ }^{*}$ Missing Data for Age and Gender: Total = 8, Anterior Uveitis = 5, Others = 3

ones, except for the patient with history of CMV anterior uveitis, who presented with intermediate uveitis after vaccination. One patient $(7.7 \%)$ had persistent visual loss on the last follow-up due to cystoid macular oedema in intermediate uveitis (VA reduced $\leq 3$ lines).

Regarding the management of the events, 39 patients (55.7\%) received only topical corticosteroids, 13 (18.6\%) received systemic corticosteroids (five of them also received topical corticosteroids and four antibiotics), 10 $(14.3 \%)$ did not require any treatment, six (8.6\%) received antivirals (two of them with topical corticosteroids), and two (2.8\%) received topical corticosteroids with oral non-steroidal anti-inflammatory drugs (NSAI Ds). Three patients (4.3\%) required IOP lowering medications (two with glaucomatocyclitic crisis and one with CMV anterior uveitis) and one (1.4\%) initiated methotrexate after the episode (giant cell arteritis).

\section{Discussion}

Although rare, development of uveitis after administration of vaccine is a known event. Cases of vaccineassociated uveitis have been reported with almost all the vaccines currently administered, including vaccines against hepatitis A and B virus, human papillomavirus, influenza virus, bacillus Calmette-Guerin, measlesmumps-rubella, varicella virus, yellow fever and Neisseria meningitides [7-18].

Ocular inflammatory events after COVID-19 vaccination from a multinational case series are described in this study. A search of Medline, using PubMed and Google Scholar, performed in August 2021, using the following keywords: 'uveitis', 'vaccination', 'COVID19', revealed six case reports and two national case series describing presumed COVID-19 vaccine-related uveitis have been reported so far, including new onset of bilateral juvenile idiopathic arthritis (JIA)-associated anterior uveitis, unilateral anterior uveitis, bilateral choroiditis complicated by subretinal fluid, bilateral panuveitis with choroidal thickening and vascular leakage, and recurrence of Vogt Koyanagi Harada (VKH) [19-26]. Rabinovitch et al. reported twenty one cases of uveitis after COVID-19 vaccination in Israel, of which nineteen were diagnosed with anterior uveitis and two developed multiple evanescent white dot syndrome (MEWDS) [24]. Recently, Pichi et al. described seven patients diagnosed with episcleritis (1), anterior scleritis (2), acute macular neuroretinopathy (AMN) (2), paracentral acute middle maculopathy (PAMM) (1), and subretinal fluid (1) after COVID-19 vaccination [25]. None of these studies was a multicentral case series. Similarly to the findings of Rabinovitch et al., we found that anterior uveitis was the most common ocular inflammatory event observed after COVID-19 vaccination, with more than 50\% of the patients having a known history of uveitis. The majority of the episodes we reported occurred after the Pfizer vaccine. These findings are probably based on the number of the administered doses. 
Table 2 Ocular Inflammatory Events Description

\begin{tabular}{|c|c|c|c|c|c|c|}
\hline & Variable & $\begin{array}{l}\text { Total } \\
(\%) \\
(\mathrm{N}= \\
70)\end{array}$ & $\begin{array}{l}\text { Anterior Uveitis } \\
(\%) \\
(\mathrm{N}=41)\end{array}$ & $\begin{array}{l}\text { Posterior Uveitis } \\
(\%) \\
(\mathrm{N}=9)\end{array}$ & $\begin{array}{l}\text { Scleritis } \\
(\%) \\
(N=7)\end{array}$ & $\begin{array}{l}\text { Others } \\
(\%) \\
(\mathrm{N}=13)\end{array}$ \\
\hline \multirow[t]{5}{*}{$\begin{array}{l}\text { Previous Ocular Inflammatory } \\
\text { Events }\end{array}$} & Number of patients & $\begin{array}{l}36 \\
(51.4)\end{array}$ & $23(56.1)$ & $3(33.3)$ & $5(71.4)$ & $5(38.5)$ \\
\hline & $\begin{array}{l}\text { Controlled more than } 3 \\
\text { months }\end{array}$ & $\begin{array}{l}28 \\
(82.4)\end{array}$ & $17(81.0)$ & $3(100)$ & $3(60.0)$ & $5(100)$ \\
\hline & On Topical Anti-inflammatory & $1(2.8)$ & $1(4.3)$ & $0(0.0)$ & $0(0.0)$ & $0(0.0)$ \\
\hline & $\begin{array}{l}\text { On Systemic Anti- } \\
\text { inflammatory }\end{array}$ & $7(19.4)$ & $4(17.4)$ & $0(0.0)$ & $1(20.0)$ & $2(15.4)$ \\
\hline & $\begin{array}{l}\text { Event similar to previous } \\
\text { events }\end{array}$ & $\begin{array}{l}34 \\
(94.4)\end{array}$ & $23(100.0)$ & $2(66.7)$ & $5(100.0)$ & $4(80)$ \\
\hline \multirow[t]{5}{*}{ Presentation } & Unilateral & $\begin{array}{l}60 \\
(85.7)\end{array}$ & $33(80.5)$ & $8(88.9)$ & $7(100)$ & $12(92.3)$ \\
\hline & Bilateral & $\begin{array}{l}10 \\
(14.3)\end{array}$ & $8(19.5)$ & $1(11.1)$ & $0(0.0)$ & $1(7.7)$ \\
\hline & VA Unaffected & $\begin{array}{l}38 \\
(54.3)\end{array}$ & $22(53.7)$ & $2(22.2)$ & $6(85.7)$ & $8(61.5)$ \\
\hline & VA reduced $\leq 3$ lines & $\begin{array}{l}18 \\
(25.7)\end{array}$ & $10(24.4)$ & $4(44.4)$ & $1(14.3)$ & $3(23.1)$ \\
\hline & VA reduced $>3$ lines & $\begin{array}{l}14 \\
(20.0)\end{array}$ & $9(22.0)$ & $3(33.3)$ & $0(0.0)$ & $2(15.4)$ \\
\hline \multirow[t]{5}{*}{ Management } & Topical Corticosteroids & $\begin{array}{l}48 \\
(68.6)\end{array}$ & $34(82.9)$ & $3(33.3)$ & $6(85.7)$ & $5(38.5)$ \\
\hline & Systemic Corticosteroids & $\begin{array}{l}13 \\
(18.6)\end{array}$ & $2(4.9)$ & $6(66.7)$ & $1(14.3)$ & $4(30.8)$ \\
\hline & Antivirals & $6(8.6)$ & $5(12.2)$ & $0(0.0)$ & $0(0.0)$ & $1(7.7)$ \\
\hline & NSAIDs & $2(2.9)$ & $0(0.0)$ & $0(0.0)$ & $1(14.3)$ & $1(7.7)$ \\
\hline & Antibiotics & $4(5.7)$ & $0(0.0)$ & $4(44.4)$ & $0(0.0)$ & $0(0.0)$ \\
\hline \multirow[t]{3}{*}{ Visual Outcomes } & VA Unaffected & $\begin{array}{l}65 \\
(92.9)\end{array}$ & $39(95.1)$ & $7(77.8)$ & $7(100)$ & $12(92.3)$ \\
\hline & VA reduced $\leq 3$ lines & $2(2.9)$ & $1(2.4)$ & $0(0.0)$ & $0(0.0)$ & $1(7.7)$ \\
\hline & VA reduced $>3$ lines & $3(4.3)$ & $1(2.4)$ & $2(22.2)$ & $0(0.0)$ & $0(0.0)$ \\
\hline \multirow[t]{4}{*}{ Complications } & Transient IOP elevation & $3(4.3)$ & $3(7.3)$ & $0(0.0)$ & $0(0.0)$ & $0(0.0)$ \\
\hline & Nummular Corneal Lesions & $1(1.4)$ & $1(2.4)$ & $0(0.0)$ & $0(0.0)$ & $0(0.0)$ \\
\hline & Cystoid Macular Oedema & $2(2.9)$ & $1(2.4)$ & $0(0.0)$ & $0(0.0)$ & $1(7.7)$ \\
\hline & Macular Scarring & $2(2.9)$ & $0(0.0)$ & $2(22.2)$ & $0(0.0)$ & $0(0.0)$ \\
\hline
\end{tabular}

The potential mechanism underlying the ocular inflammation response following COVID-19 vaccination is not known. Commonly proposed mechanisms include (1) molecular mimicry secondary to resemblance between uveal peptides and vaccine peptide fragments, (2) antigen-specific cell and antibody-mediated hypersensitivity reactions, (3) inflammatory damage induced by adjuvants included the vaccines stimulating innate immunity through endosolic or cytoplasmic nucleic acid receptors [18, 27-30].

The Bradford-Hill criteria include nine aspects to consider when inferring causality between events: (1) strength of the association, (2) consistency, (3) specificity, (4) temporality, (5) biological gradient, (6) plausibility, (7) coherence, (8) experiment, and analogy (9) [31]. The design of this study guarantees temporality, since there was a short interval of time following vaccination and the onset of the events. The fact that among 18 patients who had an event following the first dose and still received a second dose, 6 (33.3\%) presented similar events following the second dose, as well as different observations in different regions from different people, supports consistency (reproducibility) between exposure and outcome. The causality is plausible as some biological mechanisms have already been proposed. Finally, the events after COVID-19 vaccination 
are analogous to those reported following other vaccines.

From our study it emerged that most of the inflammatory episodes were not severe, and patients were mainly managed with topical corticosteroids or observation only (70\%), with unaffected final visual acuity (92.9\%). Very few patients developed ocular complications resulting in tissue damage and visual loss (7.1\%), including corneal opacity, cystoid macular oedema and macular scarring.

Study limitations include its observational and noncontrolled nature, that cannot be used to infer causality because it does not allow to stablish strength of the association, specificity, biological gradient, coherence, nor experiment. Additionally, there is a potential sample bias due to the form of data collection, and the data collected might not be representative of all population, although the multicentre nature of the study need to be considered as it may reduce the bias.

\section{Conclusion}

Hereby we report a large multinational case series of ocular inflammatory events occurred following COVID19 vaccination, based on a temporal and multicentrical association, but not proving causality. Even in the possibility of of a causal association, most of the events were mild and had a good visual outcome. Therefore, there is no evidence from this study to suggest that individuals should avoid getting vaccinated because of ophthalmicrelated adverse events. It is not the aim of the authors to impede or curtail the vaccination efforts, but rather to educate physicians and patients about rare but potential ocular inflammatory events after the COVID-19 vaccination.

\section{Abbreviations}

FDA: Food and drug administration; EMA: European medicines agency; mRNA: Messenger RNA; AZOOR: Acute zonal occult outer retinopathy; VA: Visual acuity; CMV: Cytomegalovirus; NSAIDs: Non-steroidal antiinflammatory drugs; JIA: Juvenile idiopathic arthritis; VKH: Vogt Koyanagi Harada; MEWDS: Multiple evanescent white dot syndrome; AMN: Acute macular neuroretinopathy; PAMM: Paracentral acute middle maculopathy

\section{Acknowledgements}

We would like to acknowledge the International Ocular Inflammation Society (IOIS) and International Uveitis Study Group (IUSG) for supporting the project.

\section{*Group Information.}

The COVID-19 Vaccination Ocular Inflammatory Events Study Group members are: Laura Steeples, Manchester Royal Eye Hospital, Manchester, UK; Balini Balasubramaniam, Queen Elizabeth Hospital, Birmingham, UK; Peter McCluskey, The University of Sydney, Save Sight Institute, Sydney, Australia; Francesco Pichi, Cleveland Clinic Abu Dhabi, UAE; Aniruddha Agarwal, Cleveland Clinic Abu Dhabi, UAE; Carl Herbort, COS, Lausanne, Switzerland; Luca Cimino, Arcispedale S. Maria Nuova, Reggio Emila, Italy; Salam Iriqat, St John of Jerusalem Eye Hospital, Jerusalem, Israel; Jennifer E. Thorne, Wilmer Eye Institute, Johns Hopkins University School of Medicine, Baltimore, MD, USA; Jose Echegaray, Case Western Reserve University in Cleveland, OH, USA; Kalpana Babu, Prabha eye clinic and research centre \& Vittala Institute of Ophthalmology, Bangalore, India; Alexander Arthur Bialasiewicz, Al-Ahli Hospital, Doha, Qatar; Debra A. Goldstein, Northwestern Feinberg School of
Medicine, Chicago, IL, USA; Nima Ghadiri, Liverpool University Hospital, Liverpool, UK; Alex Fonollosa Calduch, Hospital Universitario Cruces, Universidad del País Vasco, Instituto Oftalmológico Bilbao, Bilbao, Spain; Gabriel Costa de Andrade; Padmamalini Mahendradas, Narayana Nethralaya, Bangalore, India; Julio J González-López, Hospital Ramón y Cajal, Madrid, Spain; Ester Carreño, Hospital Universitario Fundacion Jimenez Diaz, Madrid, Spain; Rola N Hamam, American University of Beirut, Lebanon; Nicole Stübiger, Universitätsklinikum Hamburg-Eppendorf, Augenklinik, Germany; Bahram Bodaghi, Sorbonne Université, Hôpital de la Pitié-Salpêtrière, Paris, France; Yu-Jang Chao, Cheng Hsin General Hospital, Taipei, Taiwan; Masaru Takeuchi, National Defense Medical College, Namiki Tokorozawa Saitama, Japan; Mei-Ling Tay-Kearney, Lions Eye Institute, Royal Perth Hospital, Perth, WA, USA; Alejandro Portero, Hospital Universitario La Zarzuela, Madrid, Spain; Hiroshi Keino, Kyorin University School of Medicine, Tokyo, Japan; Padmamalini Mahendradas, Narayana Nethralaya, Bangalore; Mar Esteban-Ortega, Hospital Infanta Sofia, San Sebastian de los Reyes, Madrid, Spain; Joanna Przeździecka-Dołyk, Wrocław Medical University, Wroclaw, Poland; Aleksandra Radosavljević, University Clinical Center of Serbia, Belgrade, Serbia; Ian Paredes, Legaspi Eye Center, Legaspi, Bicol, Philippines and Chua Eye Center, Angeles, Pampanga, Philippines; Rupesh Agrawal, National Healthcare Group Eye Institute, Tan Tock Seng Hospital, Singapore; Ho Su Ling, National Healthcare Group Eye Institute, Tan Tock Seng Hospital, Singapore; Wei Kiong, National Healthcare Group Eye Institute, Tan Tock Seng Hospital, Singapore; Melissa Tien, National Healthcare Group Eye Institute, Tan Tock Seng Hospital, Singapore; Xin Le Ng, National Healthcare Group Eye Institute, Tan Tock Seng Hospital, Singapore; Carlos Pavesio, Moorfields Eye Hospital, NHS Foundation Trust, London, UK; Ilaria Testi, Moorfields Eye Hospital, NHS Foundation Trust, London, UK; Soon Phaik Chee, Singapore National Eye Centre, Singapore; Jay Siak, Singapore National Eye Centre, Singapore; Ines Hernanz-Rodriguez, Hospital Universitario Fundacion Jimenez Diaz, Madrid, Spain; Victor Menezo, Institut Catala de Retina, BarceIona, Spain; Christoph Tappeiner, Department of Ophthalmology, Pallas Kliniken, Olten, Switzerland; Franz Marie Cruz, Peregrine Eye and Laser Institute, Makati, Philippines; Peter Addison, London, UK; Robert Kuijpers, Universitair Ziekenhuis Brussel, Vrije Universiteit Brussel, Brussels, Belgium; Daniel Vitor Vasconcelos-Santos, Universidade Federal de Minas Gerais, Belo Horizonte, Brazil.

\section{Authors' contributions}

Conception and design: Pavesio, Testi, Agrawal. Analysis and interpretation: Brandão-de-Resende, Pavesio, Testi, Agrawal. Overall responsibility: Pavesio, Testi, Agrawal, Brandão-de-Resende. The authors read and approved the final manuscript.

Funding

None.

Availability of data and materials

All the data pertaining to the cases are available with the corresponding author.

\section{Declarations}

\section{Consent for publication}

The IRB/ethics committee approved this study. All research adhered to the tenets of the Declaration of Helsinki. The requirement for informed consent was waived because of the retrospective nature of the study.

\section{Competing interests}

The authors have no relevant affiliations or financial involvement with any organization or entity with a financial interest in or financial conflict with the subject matter or materials discussed in the manuscript. This includes employment, consultancies, honoraria, stock ownership or options, expert testimony, grants or patents received or pending, or royalties.

\section{Author details}

${ }^{1}$ Department of Uveitis, Moorfields Eye Hospital, NHS Foundation Trust, London, UK. ${ }^{2}$ Clinical Research Facility, Moorfields Eye Hospital, NHS Foundation Trust, London, UK. ${ }^{3}$ National Healthcare Group Eye Institute, Tan Tock Seng Hospital, Singapore, Singapore. ${ }^{4}$ Singapore Eye Research Institute, Singapore, Singapore. ${ }^{5}$ Lee Kong Chian School of Medicine, Nanyang Technological University, Singapore, Singapore. ${ }^{6}$ The Ophthalmology \& Visual 
Sciences Academic Clinical Programme, Duke NUS Medical School, Singapore, Singapore.

Received: 30 October 2021 Accepted: 14 November 2021 Published online: 04 January 2022

\section{References}

1. Nasiri N, Sharifi H, Bazrafshan A, Noori A, Karamouzian M, Sharifi A (2021) Ocular manifestations of COVID-19: a systematic review and Meta-analysis. J Ophthalmic Vis Res 16(1):103-112. https://doi.org/10.18502/jovr.v16i1.8256

2. Aggarwal K, Agrawal A, Jaiswal N et al (2020) Ocular surface manifestations of coronavirus disease 2019 (COVID-19): a systematic review and metaanalysis. PLoS One 15(11):e0241661. https://doi.org/10.1371/journal.pone. 0241661

3. Seah I, Agrawal R (2020) Can the coronavirus disease 2019 (COVID-19) affect the eyes? A review of coronaviruses and ocular implications in humans and animals. Ocul Immunol Inflamm 28(3):391-395. https://doi.org/10.1080/092 73948.2020.1738501

4. Sen S, Kannan NB, Kumar J, Rajan RP, Kumar K, Baliga G, Reddy H, Upadhyay A, Ramasamy K (2021) Retinal manifestations in patients with SARS-CoV-2 infection and pathogenic implications: a systematic review. Int Ophthalmol 11:1-14. https://doi.org/10.1007/s10792-021-01996-7

5. Pepe S, Gregory AT, Denniss AR (2021) Myocarditis, Pericarditis and Cardiomyopathy After COVID-19 Vaccination. Heart Lung Circ S14439506(21):01156-01152

6. Diaz GA, Parsons GT, Gering SK, Meier AR, Hutchinson IV, Robicsek A (2021) Myocarditis and Pericarditis After Vaccination for COVID-19. JAMA:e2113443

7. Marinho PM, Nascimento H, Romano A, Muccioli C, Belfort R Jr (2019) Diffuse uveitis and chorioretinal changes after yellow fever vaccination: a reemerging epidemic. Int J Retina Vitreous 5(1):30. https://doi.org/10.1186/s4 0942-019-0180-0

8. Ng CC, Jumper JM, Cunningham ET Jr (2020) Multiple evanescent white dot syndrome following influenza immunization - a multimodal imaging study. Am J Ophthalmol Case Rep 19:100845. https://doi.org/10.1016/j.ajoc.2020.1 00845

9. Jorge LF, Queiroz RP, Gasparin F, Vasconcelos-Santos DV (2020) Presumed unilateral acute idiopathic maculopathy following H1N1 vaccination. Ocul Immunol Inflamm:1-3. https://doi.org/10.1080/09273948.2020.1734213

10. Campos WR, Cenachi SPF, Soares MS, Gonçalves PF, Vasconcelos-Santos DV (2021) Vogt-Koyanagi-Harada-like Disease following Yellow Fever Vaccination. Ocul Immunol Inflamm 29(1):124-127

11. Sood AB, O'Keefe G, Bui D, Jain N (2019) Vogt-Koyanagi-Harada disease associated with hepatitis B vaccination. Ocul Immunol Inflamm 27(4):524527. https://doi.org/10.1080/09273948.2018.1483520

12. Abou-Samra A, Tarabishy AB (2019) Multiple evanescent white dot syndrome following intradermal influenza vaccination. Ocul Immunol Inflamm 27(4):528-530. https://doi.org/10.1080/09273948.2017.1423334

13. Biancardi AL, Moraes HV Jr (2019) Anterior and intermediate uveitis following yellow fever vaccination with fractional dose: case reports. Ocul Immunol Inflamm 27(4):521-523. https://doi.org/10.1080/09273948.2018.151 0529

14. Benage M, Fraunfelder FW (2016) Vaccine-associated uveitis. Mo Med 113(1): 48-52

15. Holt HD, Hinkle DM, Falk NS, Fraunfelder FT, Fraunfelder FW (2014) Human papilloma virus vaccine associated uveitis. Curr Drug Saf 9(1):65-68. https:// doi.org/10.2174/15748863113086660062

16. Fraunfelder FW, Suhler EB, Fraunfelder FT (2010) Hepatitis B vaccine and uveitis: an emerging hypothesis suggested by review of 32 case reports. Cutan Ocul Toxicol 29(1):26-29. https://doi.org/10.3109/1556952 0903427717

17. Escott S, Tarabishy AB, Davidorf FH (2013) Multifocal choroiditis following simultaneous hepatitis a, typhoid, and yellow fever vaccination. Clin Ophthalmol 7:363-365. https://doi.org/10.2147/OPTH.S37443

18. Cunningham ET Jr, Moorthy RS, Fraunfelder FW, Zierhut M (2019) Vaccineassociated uveitis. Ocul Immunol Inflamm 27(4):517-520. https://doi.org/10.1 080/09273948.2019.1626188

19. Papasavvas I, Herbort CP Jr (2021) Reactivation of Vogt-Koyanagi-Harada disease under control for more than 6 years, following anti-SARS-CoV-2 vaccination. J Ophthalmic Inflamm Infect 11(1):21. https://doi.org/10.1186/ s12348-021-00251-5
20. ElSheikh RH, Haseeb A, Eleiwa TK, Elhusseiny AM (2021) Acute uveitis following COVID-19 vaccination. Ocul Immunol Inflamm 11:1-3. https://doi. org/10.1080/09273948.2021.1962917

21. Goyal M, Murthy SI, Annum S (2021) Bilateral multifocal choroiditis following COVID-19 vaccination. Ocul Immunol Inflamm Aug 3:1-5. https://doi.org/1 0.1080/09273948.2021.1972716

22. Mudie LI, Zick JD, Dacey MS, Palestine AG (2021) Panuveitis following vaccination for COVID-19. Ocul Immunol Inflamm Jul 2(4):1-2. https://doi. org/10.1080/09273948.2021.1949478

23. Renisi G, Lombardi A, Stanzione M, Invernizzi A, Bandera A, Gori A (2021) Anterior uveitis 19 onset after bnt162b2 vaccination: is this just a coincidence? Int J Infect Dis 110:95-97

24. Rabinovitch T, Ben-Arie-Weintrob Y, Hareuveni-Blum T, Shaer B, VishnevskiaDai V, Shulman S, Newman H, Biadsy M, Masarwa D, Fischer N, Yovel O, Ben Zaken SG, Habot-Wilner Z (2021) Uveitis following the BNT162b2 mRNA vaccination against SARS-CoV-2 infection: a possible association. Retina 2. https://doi.org/10.1097//AE.0000000000003277

25. Pichi F, Aljneibi S, Neri P, Hay S, Dackiw C, Ghazi NG (2021) Association of Ocular Adverse Events with Inactivated COVID-19 vaccination in patients in Abu Dhabi. JAMA Ophthalmol 2(10):1131. https://doi.org/10.1001/jama ophthalmol.2021.3477

26. Saraceno JJF, Souza GM, Dos Santos Finamor LP, Nascimento HM, Belfort $R$ Jr (2021) Vogt-Koyanagi-Harada syndrome following COVID-19 and ChAdOx1 nCoV-19 (AZD1222) vaccine. Int J Retina Vitreous. 7(1):49. https:// doi.org/10.1186/s40942-021-00319-3

27. Watad A, De Marco G, Mahajna H et al (2021) Immune-Mediated Disease Flares or New- Onset Disease in 27 Subjects Following mRNA/DNA SARSCoV-2 Vaccination. Vaccines (Basel) 9(5):435

28. Teijaro JR, Farber DL (2021) COVID-19 vaccines: modes of immune activation and future challenges. Nat Rev Immunol 21(4):195-197. https:// doi.org/10.1038/s41577-021-00526-x

29. Rodero MP, Crow YJ (2016) Type I interferon-mediated monogenic autoinflammation: The type I interferonopathies, a conceptual overview. J Exp Med 213(12):2527-2538

30. Cunningham ET Jr, Moorthy RS (2020) Vaccine-associated posterior uveitis. Retina 40(4):595-598. https://doi.org/10.1097/IAE.0000000000002816

31. Hill $A B$ (1965) The environment and disease: association or causation? Proc R Soc Med 58(5):295-300. https://doi.org/10.1177/003591576505800503

\section{Publisher's Note}

Springer Nature remains neutral with regard to jurisdictional claims in published maps and institutional affiliations.

\section{Submit your manuscript to a SpringerOpen ${ }^{\circ}$ journal and benefit from:}

- Convenient online submission

- Rigorous peer review

- Open access: articles freely available online

- High visibility within the field

- Retaining the copyright to your article

Submit your next manuscript at $>$ springeropen.com 